\title{
A precarização da educação pública formal no Estado de São Paulo: alienação e estranhamento no trabalho pedagógico
}

Rafael Rossi ${ }^{1}$

\section{Resumo}

Neste artigo, problematizo o processo de precarização do trabalho pedagógico no âmbito das escolas públicas do Estado de São Paulo. Para avançar nessa investigação, utilizo a contribuição do método marxista de análise no campo educacional, discutindo a questão da alienação e do estranhamento no trabalho pedagógico. O presente texto é fruto de observações de vivência empírica da profissão docente da educação formal básica pública e, também, de pesquisa bibliográfica sobre o assunto. Nele, defendo que resgatar uma reflexão atual sobre o Estado Capitalista, demonstrando a relevância do papel histórico da luta de classes, é um caminho promissor na urgente tarefa de mobilização pela garantia à educação de qualidade. Por isso, é necessário reorganizar o espaço escolar como local de formação política.

\section{Palavras-chave}

Alienação. Estranhamento. Trabalho Pedagógico. Educação.

1. Doutorando em Educação pela Faculdade de Ciências e Tecnologia da Universidade de São Paulo (Campus de Presidente Prudente), pesquisador do Grupo de Estudos e Pesquisas em Educação Popular (GEPEP) vinculado ao Departamento de Educação da mesma instituição. E-mail: rafaelrossi6789@hotmail.com. 


\title{
The precarious formal public education in São Paulo: alienation and estrangement in pedagogical work
}

Rafael Rossi*

\begin{abstract}
In this article, I analyze the process of pedagogical work precarious situation concerning the public schools in São Paulo. To move forward with this research, the contribution of the Marxist analysis method has been used in the educational field, discussing the alienation issue and pedagogical work problematic. This text is the result of observations from teaching profession empirical experience of public basic formal education, and a literature on the subject. Through this article, I argue that we rescue reflection on the current capitalist state, demonstrating the relevance of the class struggle historical role, is a promising way in the urgent task of mobilizing for ensuring quality education. Then, we need to reorganize the school as a place of political education.
\end{abstract}

\section{Keywords}

Alienation. Estrangement. Pedagogical Work. Education.

* Candidate for a doctor's degree in Education at the Faculty of Sciences and Techonology at the University of São Paulo (Presidente Prudente Campus), Studies and Research in Popular Education (GEPEP) researcher, bound to Educational Department at the same institution. E-mail: rafaelrossi6789@hotmail.com. 


\section{Introdução}

O ensino público formal no Estado São Paulo está desencadeando um franco e acelerado processo de precarização do trabalho pedagógico. Essa é uma tese que não agrada a todos! No entanto, os elementos da realidade que fundamentam tal argumentação são passíveis de observação a qualquer pesquisador, basta vontade política científica para "sair da bolha acadêmica". Por trabalho pedagógico estou entendendo toda estrutura e características das práticas de gestores e professores, isto é, as tarefas e os esforços que organizam uma escola. É importante afirmar que não há teoria que se sustente sem análise rigorosa da realidade, por isso a necessidade de interpretação do empírico, ou seja, a sistematização e a problematização do fenômeno em estudo. Em outras palavras: "É preciso sair da bolha!", em especial quando o tema é educação pública, para não incorrermos no risco de reproduzir e disseminar uma visão romântica do ambiente educacional.

Não é possível, ou melhor, é despolitizado assentarmos em uma postura de "gárgula" quando discutimos a educação. Não podemos ficar analisando "de cima", imponentes na altura de nossas verdades, olhando para a realidade como que do alto, intentando uma neutralidade erroneamente interpretada como científica. Como já nos ensinou pensadores como Paulo Freire e István Mészáros, a tida "neutralidade" não existe e não devemos negar a politicidade da educação, nem a educabilidade do ato político.

É importante esclarecer que não me insiro nessa discussão apenas com base em leituras e reflexões bibliográficas. Atualmente, também atuo como professor da rede pública estadual e problematizo a questão educacional na atualidade a partir da vivência neste quesito, além de acreditar que o método marxista instiga a mobilização e o engajamento, em um esforço da reflexão do cotidiano escolar a partir dos embates e disputas de interesses entre os grupos privados que intentam a privatização da educação. Ainda há pouco tempo, ficava indignado e contrariado quando algum professor da rede pública afirmava que mestrandos, doutorandos e professores universitários viviam em outra esfera, separados, isolados no mundo das ideias. Entretanto, é realmente lamentável observar alguns pesquisadores educacionais de universidades públicas fartarem-se em seus artigos, teses e palestras de argumentos e citações de pensadores como Paulo Freire, Makarenko, Pestalozzi, Florestan Fernandes etc. e, no diaa-dia, praticarem mecânica e sistematicamente a educação bancária (de acordo com a crítica da perspectiva freireana) em seus múltiplos aspectos e abordagens. Tais pesquisadores se encontram como a pedra no fundo de uma lagoa, circundados pela água e secos por dentro, demonstrando, a partir de suas realizações práticas, a insensibilidade perante aos desafios do trabalho pedagógico. Não é surpreendente que:

\begin{abstract}
A competência técnico-científica de que o professor não deve abrir mão do seu trabalho não são incompatíveis com a amorosidade necessária às relações educativas. Essa postura ajuda o ambiente favorável à produção do conhecimento onde o medo do professor e o mito que se cria em torno da sua pessoa vão sendo desvalados. É preciso aprender a ser coerente. De nada adianta o discurso competente se a ação pedagógica é impermeável às mudanças. (FREIRE, 1996, p. 4).
\end{abstract}

Assim sendo, tenho por objetivo problematizar a educação formal do Estado de São Paulo, explicitando o vigente processo de precarização do trabalho pedagógico e apontando a necessidade de pensarmos coletivamente em ações que promovam maior união entre a classe trabalhadora. Para 
tanto, divido este texto em mais três partes: na primeira, acredito ser importante resgatar uma reflexão sobre o Estado Capitalista, a fim de atentar para sua estrutura quase que "geneticamente" intencionada a atender os interesses das classes dominantes e, também, para explicitar a relevância do papel da luta de classes na história da humanidade. Na segunda parte, argumento sobre a educação como campo recentemente incorporado às tramas mercadológicas de reprodução do capital, a partir do crescente interesse de grupos privados na sua gerência e controle. Avanço no sentido de denunciar elementos da realidade das escolas públicas estaduais que fundamentam e estruturam a dinâmica precarizante do trabalho pedagógico, implicando na concretude de sua alienação e estranhamento. Já na terceira parte, teço minhas considerações finais sobre a polêmica aqui em debate. Dessa maneira, de modo algum pretendo menosprezar demais análises sobre a questão educacional. Acredito no potencial e na urgência de propormos uma reflexão atual sobre a dimensão política da educação, com o objetivo de desmascararmos discursos e unirmos esforços rumo a condições mais dignas e com mais qualidade do trabalho pedagógico em âmbito estadual e nacional. Portanto, essa crítica aqui realizada também se manifesta como potencial para a ação, conforme o pensamento contido na frase atribuída a Pierre Beaumarchais: "Sem liberdade de criticar, não existe elogio sincero".

\section{O Estado capitalista: a relevância da luta de classes em questão}

Antes de aprofundar o debate sobre a importância da luta de classes como questão fundamental para a tomada de posicionamento perante os agentes que desenvolvem o trabalho pedagógico nas escolas públicas, considero necessário entender e resgatar a discussão marxista do Estado capitalista em sua tendência quase "genética" a favorecer os interesses das classes dominantes.

Optamos por trazer à discussão uma definição de Estado, mesmo que ainda preliminar, para prosseguir a problematização, já que se trata de um debate mais amplo e que perpassa o de políticas públicas. De acordo com o Dicionário do Pensamento Marxista editado por Tom Bottomore (2001), trata-se de um conceito de fundamental relevância para o marxismo, compreendendo sua função a fim de assegurar e conservar a dominação e exploração de classe. Engels em seu livro "A origem da família, da propriedade privada e do Estado" afirma que o Estado é:

[...] em geral, o Estado da classe mais poderosa, economicamente dominante, que por meio dele, torna-se igualmente a classe politicamente dominante, adquirindo, com isso, novos meios de dominar e explorar a classe oprimida. (ENGELS apud BOTTOMORE, 2001, p. 134).

E ainda,

O marxismo clássico e o leninismo sempre ressaltaram o papel coercitivo do Estado, quase que com a exclusão de todos os outros aspectos: o Estado é essencialmente a instituição pela qual uma classe dominante e exploradora impõe e defende seu poder e seus privilégios contra a classe ou classes que domina e explora. (BOTTOMORE, 2001, p. 136).

As proposições de Gramsci (1976) permitem alargar o debate, na medida em que este autor apresenta argumentos para superar a compreensão "ingênua" de política. Para o autor, entender a política de maneira superficial e corriqueira como uma política parlamentar empobrece o conceito de Estado. Esse, por sua vez, apresenta as tramas, intrigas, jogos e relações de poder, por meio dos quais aqueles que estão sob sua atenção tornam-se, além de dominados, uma consciência coletiva que aceita as decisões tomadas e impostas. O autor avança em relação ao entendimento clássico de Estado 
do marxismo, por entendê-lo como disputa entre classes sociais para o exercício da hegemonia².

Gramsci (1976) entende dois grandes grupos e/ou tipos de política: a grande política e a pequena política. A primeira refere-se a questões estruturadoras de manutenção e atuação entre os Estados; a segunda materializase nas opções e escolhas, consolidadas por meio dos legisladores e imbuídas de interesses resultantes de embates e lutas no interior do Estado, que se realiza no cotidiano, contribuindo para a manutenção do exercício do poder. $\mathrm{O}$ autor explicita como os interesses da classe dominante podem se manifestar em práticas organizadas e implantadas pelo Estado, com a aceitação dos governados, com intuito de prevalecer como classe hegemônica. É por esse viés que podemos compreender como a educação pública no Estado de São Paulo opera de maneira a garantir o consentimento de professores e gestores.

Gramsci (1976) apresenta importante contribuição no entendimento das ações do Estado, dentre elas a política como resultado de conflitos e disputas internas entre os grupos que se estruturam em seu interior. Isso possui relação direta com a constatação de que muitos fatos e acontecimentos devem-se às estratégias e práticas consolidadas pela materialização de outros grupos, chamados de "privados", que podem vir a compor a hegemonia do Estado. Para Gramsci, o Estado implica em força e consenso, isto é, além de estar conivente e a favor de uma classe dominante, a dominação também se dá de forma mais sutil e eficaz por meio do consenso.

É a essa contribuição que precisamos estar atentos, isto é, ao fato de que o Estado serve de instrumento à garantia dos interesses das classes dominantes, o que só se realiza a partir do consentimento. Isto nos permite refletir sobre a aceitação da classe trabalhadora de ideias e práticas que não correspondem e não são coerentes com seus próprios interesses de classe, mas sim aos de seus opressores. Esse processo ganha importância em tempos de globalização enquanto perversidade, tal como ensinou Santos (2011), o papel desempenhado pelas propagandas, telejornais, sites, aplicativos móveis etc., já que estilos de vida e sonhos de consumo são constantemente inculcados na classe trabalhadora, inclusive, no sentido de fortalecer o individualismo e desestimular a prática de reivindicações coletivas.

Coutinho (1984) explicita a complexidade inerente ao Estado com relação aos grupos que se estruturam em seu interior, em uma série de conflitos e embates. Assim, as relações de poder entre esses grupos tornaram-se mais complexas e densas graças à formação de alianças para promover a garantia de objetivos e ambições partilhadas.

No entanto, a partir das proposições dos autores aqui em debate, infiro o caráter de resistência e luta de classes que alguns movimentos desenvolvem na área de educação, como garantia desse direito universal à população. Exemplo disso é a discussão e a luta pela educação do campo. Trata-se de uma luta dos movimentos sociais, em especial do Movimento dos Trabalhadores Rurais Sem Terra (MST), que vem ganhando notoriedade e amplitude por seu caráter reivindicatório de uma educação com infraestrutura necessária para desenvolver uma consciência crítica no campo, sem, contudo, os educandos camponeses terem que se deslocar para escolas localizadas nas periferias urbanas.

Como um dos resultados dessas lutas, está o Programa Nacional de Educação na Reforma

2. De acordo com Gramsci, para uma classe manter seu domínio sobre as demais, além da organização da força, ela tem de avançar em estratégias que não se prendam somente em seus interesses específicos, realizando concessões e obtendo aliados unificados em um bloco histórico. Este bloco representa um consentimento para uma ordem social, em que a hegemonia da classe dominante é criada e recriada nas relações sociais e nas ideias. Dessa forma a classe hegemônica é também política, já que supera seus interesses econômicos imediatos, representando o "avanço universal da sociedade". (BOTOMORE, 2001, p. 178). 
Agrária (PRONERA), oriundo de um debate coletivo ocorrido no I Encontro Nacional de Educadores na Reforma Agrária (ENERA). Neste encontro, estiveram presentes, além do próprio MST, representantes da Universidade de Brasília (UnB), Conferência Nacional de Bispos do Brasil (CNBB), Organização das Nações Unidas para a Educação, Ciência e Cultura (UNESCO) e Fundo das Nações Unidas para a Infância (UNICEF), com o intuito de ampliar a escolarização formal dos trabalhadores rurais, em uma prerrogativa que compreende o campo como território de vida e de trabalho dos camponeses e não somente local do agronegócio, conforme Caldart (2012).

Além do PRONERA, as Diretrizes Operacionais Básicas das Escolas no Campo (2002 e 2008) e o Decreto no 7.352, que institui a Política Nacional de Educação do Campo, explicitam nitidamente o papel da luta de classes na garantia de patamares mais efetivos do direito à educação. Não é surpreendente que, em várias entrevistas, João Pedro Stédile afirme a educação do campo como uma pedagogia do exemplo, já que mostra à sociedade civil as contradições e injustiças do modo de produção capitalista e a urgência da mobilização popular como estratégia de reivindicação. É essa consciência crítica e política de luta que se encontra em franca desestabilização nos profissionais da educação pública.

O método marxista de análise parte da concepção de totalidade, não fragmentando de maneira irracional e ilógica os fatos sociais, isolando-os de maneira precipitada e despreocupada a fim de contribuir para uma especialização técnica administrativa das Ciências Humanas. Daí decorre o fato de analisar a questão da educação pública no Estado de São Paulo a partir das intencionalidades das classes dominantes para a classe trabalhadora.

Apesar de uma ampla e maciça propaganda de melhoria do ensino, as condições práticas e reais do trabalho pedagógico conformam-se somente em um processo precarizante, que estimula as escolas a uma gestão hermética perante intervenções de demais setores da sociedade e que se preocupa somente com a classificação em avaliações e índices de toda ordem, como abordo no próximo item, momento em que também discorro sobre alienação e estranhamento no trabalho pedagógico.

\section{Precarização do trabalho pedagógico: a} alienação e o estranhamento na educação

Pensar a educação como processo, implica pensá-la e assumi-la do ponto de vista de sua transitoriedade, desenvolvimento e construção. Não se encontram encerradas as chances e possibilidades de efetivação de um cenário mais justo e com maior qualidade educacional, apesar do desenvolvimento perverso e contraditório do modo de produção capitalista vigente na atualidade. Justamente pelas condições materiais de vida da maior parte da classe dos trabalhadores estarem em um nível de exigência profissional e em uma "camuflada", porém real, lógica de exploração, é que surgem as potencialidades de uma elaboração coletiva mais democrática no campo educacional. A ideia de processo remete à consideração da história a partir de sua abertura para o novo, como nos esclarece Paulo Freire (2001). A multidimensionalidade, por sua vez, presente na educação, se dá em uma prerrogativa que admite e aprende com a realidade diversa dos educandos. Isso afirma uma constatação de que outras esferas da vida social implicam diretamente no campo educacional. Se o serviço público de saúde não está bem organizado e conseguindo oferecer um atendimento de qualidade, a educação fica afetada. Daí a necessidade de aprofundarmos no estudo do método marxista em educação e retornarmos para a questão da totalidade e das desigualdades do modo de produção capitalista.

Ao invés da discussão sobre a educação pública estadual nos permitir retomar a 
questão das desigualdades sociais e da luta de classes dos trabalhadores ${ }^{3}$, em alguns casos, caminha-se para um rumo em que os termos "capacitação técnica", "profissionalização" e "empreendedorismo" aparecem como "salvadores da pátria", formas capazes de contribuir para uma educação crítica elibertadora em que o mercado passa a ser a lógica estruturante dessa pedagogia, preocupada em atender as demandas do desenvolvimento do capital. A partir dessa constatação analisaremos o trecho:

O trabalho é externo (äusserlich) ao trabalhador, isto é, não pertence ao seu ser, que ele não se afirma, portanto, em seu trabalho, mas nega-se nele, que não se sente bem, mas infeliz, que não desenvolve nenhuma energia física e espiritual livre, mas mortifica sua physis e arruína o seu espírito. O trabalhador só se sente, por conseguinte e em primeiro lugar, junto a si [quando] fora do trabalho e fora de si [quando] no trabalho. Está em casa quando não trabalha e, quando trabalha, não está em casa. O seu trabalho não é, portanto, voluntário, mas forçado, trabalho obrigatório. O trabalho não é, por isso, a satisfação de uma carência, mas somente um meio para satisfazer necessidades fora dele. Sua estranheza (Fremdheit) evidencia-se aqui [de forma] tão pura que, tão logo inexista coerção física ou outra qualquer, foge-se do trabalho como de uma peste. O trabalho externo, o trabalho no qual o homem se exterioriza, é um trabalho de auto-sacrifício, de mortificação. (MARX, 2004, p. 82-83).

O trabalho alienado, como analisado por Marx, é atual e se estrutura de modo muito mais explorador que nos tempos da Revolução Industrial. A respeito da distinção entre alienação e estranhamento, Ranieri (2001, p. 8-9) argumenta:

A primeira [alienação - Entäusserung] está carregada de um conteúdo voltado à noção de atividade, objetivação, exteriorizações históricas do ser humano; a segunda [estranhamento - Entfremdung], ao contrário, compõe-se dos obstáculos sociais que impedem que a primeira se realize em conformidade com as potencialidades do homem, entraves que fazem com que, dadas as formas históricas de apropriação e organização do trabalho por meio da propriedade privada, a alienação apareça como um elemento concêntrico ao estranhamento. Na verdade [...], a partir do momento em que se tem, na história, a produção como alvo da apropriação por parte de um determinado segmento social distinto daquele que produz, tem-se também o estranhamento, na medida em que este conflito entre a apropriação e expropriação é aquele que funda a distinção socioeconômica e também política entre as classes.

Percebe-se um sentido prático da atividade física e objetiva do trabalho, mais relacionada com a ideia de alienação e uma concepção de estranhamento que se articula com a de alienação e com a existência da propriedade privada. Marx (2004) entende que o estranhamento se materializa na vida cotidiana e no fato de o trabalhador se encontrar expropriado de qualquer propriedade, inclusive dos meios de produção. Quando ele não se encontra expropriado, ocorre a exploração, já que somente será dono de sua força de trabalho para vendê-la ao mercado e, justamente quando a estiver exercitando, ocorrerá a produção da mais-valia.

Essa discussão, quando usada na reflexão sobre o trabalho pedagógico desenvolvido nas escolas públicas, permite entendê-lo como um trabalho exploratório, que gera alienação e estranhamento, tendo como consequências:

a. Perda da consciência de classe: no caso dos professores, a fragmentação

3. O trabalho é ainda uma categoria fundamental para o debate nas pesquisas em EJA, já que os seus educandos possuem vínculos fortes e atuais com esse tema, suscitando discussões que venham a contribuir para sua organização coletiva como meta de compreenderem outras formas de gestão do trabalho (por exemplo, por meio de associações e cooperativas) e, também, para desenvolverem laços de solidariedade capazes de guiar e fomentar reivindicações mais fortes e eficazes na busca pela garantia dos direitos. 
em várias categorias $(\mathrm{O}, \mathrm{F}$, Estáveis, Não Estáveis, Efetivos etc.), no Estado de São Paulo, contribui para preocupações locais e específicas de cada categoria, perdendo-se a perspectiva de totalidade, de classe trabalhadora educacional;

b. Gestão empresarial da educação: vários grupos privados perceberam o potencial da educação na manutenção do status quo e, também, como campo de exploração a ser incorporado na lógica de produção e acumulação de capital. Práticas como a meritocracia, o estímulo à concorrência e à competitividade, a ganância e "tara" por certificados e a obsessão em melhorar os padrões da escola em alguns indicadores educacionais são exemplos de como a gestão empresarial leva a um processo de acentuação do consentimento e da fragmentação da classe trabalhadora educacional. A gestão empresarial da educação intenta também sua privatização e para isso dissemina seus produtos de modo sutil e mascarado de pesquisa, exemplo disso é a notícia com o título "Brasil fica em penúltimo lugar em ranking global de educação", que trata sobre pesquisa encomendada à consultoria britânica Economist Intellingence Unit pela empresa Pearson em seu ranking global sobre a educação, divulgada no site do jornal Folha de São Paulo, em 27 de novembro de 2012. No entanto, a Pearson intitula-se: "A maior empresa em soluções educacionais no mundo ${ }^{4 \prime}$, dona dos jornais Financial Times e The Economiste. Esta empresa também desenvolve, no Brasil, o Núcleo de Apoio à Municipalização do Ensino (NAME), congregando: "em um mesmo modelo de gestão e qualidade algumas das mais conceituadas e reconhecidas marcas da educação nacional: COC, Dom Bosco e Pueri Domus, todas pertencentes à Pearson Brasil. O compromisso NAME é levar aos alunos dos municípios conveniados os mais modernos recursos pedagógicos, tecnológicos e administrativos $\left.{ }^{5}[\ldots]\right]^{\prime \prime}$. O risco da interpretação rápida e acrítica a respeito desta pesquisa é acreditarmos que a solução dos "problemas" educacionais virá por meio de privatizações e terceirizações dos serviços desta área. Será que essa notícia foi, por acaso, disseminada de forma tendenciosa pelos jornais de mais ampla divulgação no Brasil? Será que a Pearson está realmente preocupada com o desenvolvimento do processo educacional e é isso que justifica tal ranking para classificar os 40 países escolhidos para análise? Por que os dados, avanços e ações elencadas anteriormente, seja na esfera das políticas públicas, sejam na luta dos movimentos sociais na área de Educação não foram levados em consideração na pesquisa? Precisamos estar atentos aos interesses de grupos privados que tentam disseminar uma propaganda de seus discursos e produtos de modo "mascarado" e "travestido" de pesquisa. Desmistificar ideias e discursos é compromisso assumido rumo a uma educação transformadora e que proporcione as bases para avançarmos em consciência cidadã de modo mais efetivo, democrático e menos excludente.

c. O consentimento é obtido a partir dos diversos "bônus" que as escolas e profissionais recebem quando atingem determinado grau de qualidade, eleito e

4. Informações disponíveis em: <https://www.pearson.com.br/acontece.asp?pag_id=47ধarea_pai=40दid $\mathrm{p}=0>$.

5. Para obter informações mais profundas sobre essa iniciativa mercadológica, basta acessar a página na internet da empresa, presente na nota anterior. 
avaliado pelo Estado, sendo que políticas como o FIES (Programa de Financiamento Estudantil) e o PROUNI (Programa Universidade para Todos) funcionam na prática enquanto políticas compensatórias, ou pequena política, já que, de acordo com Gramsci (1976), não apresentam perspectivas de superação das condições desiguais da educação pública nacional ${ }^{6}$.

d. Já a fragmentação se baseia em um ordenamento escolar que não facilita e não incentiva o professor a se dedicar somente a uma escola, mas sim a várias, em decorrência de uma jornada de trabalho exaustiva, já que um plano de carreira que favoreça os estudos e a preparação das aulas com qualidade nunca saiu do papel. A fragmentação também ocorre por meio das várias categorias criadas para os profissionais da educação, como já observamos e, ainda, na perda de identificação entre educadores/as universitários e da rede pública de ensino. Isto é: não se enxergam enquanto parte de uma classe, encontram-se como que batatas em um saco como na metáfora de Marx (1997).

e. Determinismo:reuniõesdepaisemque a direção centra-se na mera apresentação de dados sobre a qualificação da escola e dos alunos em índices educacionais; jornadas de trabalho exaustivas com cursos presenciais e à distância de toda ordem a professores e gestores que não promovem reflexão crítica alguma e somente contam com a participação desses agentes em função da busca por certificados como verdadeira "corrida pelo ouro", já que estes possibilitam algumas e poucas melhoras na remuneração ao longo dos anos; uma arquitetura escolar que não facilita e estimula o encontro, mas tão somente o controle e a subordinação em uma separação clara entre professores, gestores e alunos. Além disso, temos que lembrar a hipocrisia que separa o discurso da inclusão educacional de alunos com necessidades especiais e a prática escolar perversa que simplesmente os ignora e não estuda a fundo métodos e práticas para lidar com esses desafios. Esses e outros fatores correspondem a uma visão determinista da sua atividade produtiva da classe trabalhadora, reforçando o sentimento de alienação e estranhamento perante sua tarefa diária. Essa classe desunida efragmentada-recorre ao ensino particular para complementar sua renda e perde a esperança de que algum dia as coisas possam ser mudadas. Conforme Freire (2001, p. 9), “o ser determinado se acha fechado nos limites de sua determinação", e, continua o educador,

Para quem entende e vive a História como tempo de possibilidade, independentemente de se é mulher ou homem de fé, o papel dos seres humanos no mundo como sujeitos e objetos da própria história é outro. Não importa se, para elas e eles há transcendentalidade ou não, vivendo a história como tempo de possibilidade necessariamente recusam qualquer determinismo que, submetendo e minimizando a liberdade, proclama a inexorabilidade do amanhã. (FREIRE, 2001, p. 53).

A discussão sobre o determinismo e

6. Creio nesta parte do texto ser importante esclarecer que não me posiciono contra as políticas compensatórias a exemplo do FIES e PROUNI, por saber, na realidade, a importância que possuem na vida de vários jovens. No entanto, acredito também, que não houve uma reestruturação efetiva das condições de desenvolvimento do trabalho pedagógico escolar público em âmbito nacional. Se essa grande política, de acordo com Gramsci (1976), fosse implementada, não haveria a necessidade de políticas compensatórias, que no capitalismo, fortalecem o consentimento da classe trabalhadora e a hegemonia das classes dominantes. 
os pontos elencados anteriormente levam ao limite crítico do estranhamento e da alienação: a perda da utopia. Essa concepção de História apontada por Freire fica cada vez mais longínqua do horizonte de análise da classe trabalhadora educacional, basta observar suas falas em intervalos e reuniões, em ambientes cheios de catálogos de cosméticos, com revistas e jornais de ampla divulgação totalmente tendenciosos e cartazes românticos com fortes influências religiosas nas várias salas de professores existentes por aí.

De modo geral, o processo acelerado de precarização do ensino público, a partir das reflexões aqui realizadas, estrutura-se em três pilares: a meritocracia na gerência de escolas e profissionais da educação; o consentimento obtido com a ênfase em políticas compensatórias e fragmentação da classe trabalhadora educacional. Dessa forma, além de os profissionais sofrerem com isso, os alunos, em sua maioria, ficam restritos a ingressar nas universidades particulares e buscar algum financiamento ou ingressarem em escolas de ensino técnico profissionalizante e atender às demandas de qualificação da mão-de-obra do capital. Nesse sentido,

o trabalho docente deve ser compreendido como qualquer tipo de trabalho constitutivo da dinâmica da produção e reprodução social circunscrita às formações sociais capitalistas. (GONZÁLEZ; SALLES, 2008, p. 207).

Fiamengui (2009) esclarece o caso do Estado de São Paulo, com relação aos sucessivos governos do Partido da Social Democracia do Brasil - PSDB - nos últimos 16 anos. As políticas educacionais desses governos estão em completa consonância com as orientações do Banco Mundial e demais organizações internacionais que tiveram forte influência na precarização do ensino público, sobretudo sobre os aspectos relacionados à aprovação automática dos alunos e o quesito de superlotação das salas de aula. $\mathrm{O}$ autor, em sua análise, continua apontando além dos argumentos já elencados anteriormente, outras consequências do processo precarizante: jornada integralizada; baixos salários; cobranças de cima para baixo sobre a elevada aprovação dos alunos, mesmo que estes não dominem de forma razoável os conteúdos, implicando em uma educação preocupada com números; acúmulo de cargos em outras disciplinas e modalidades de ensino; alternância de cargos na educação pública e na educação privada.

A saúde do trabalhador é mais um resultado alarmante dessa lógica perversa do capital no trabalho pedagógico como alienação e estranhamento. O exercício da docência comumente envolve níveis elevados de estresse, demais psicopatologias e, inclusive, problemas locomotores e vasculares, acentuados por um esforço prolongado durante anos.

Tais perspectivas e situações apontam para a urgência da classe trabalhadora e da comunidade local da escola lograr construíla e reorganizá-la como espaço de formação intelectual e política, a partir dos conhecimentos acumulados pela humanidade historicamente e, também, a partir de discussões coletivas que problematizem suas necessidades locais, em um esforço de articular, nesse sentido, pesquisadores e instituições de pesquisa, a fim de ampliar conhecimentos sobre o cotidiano escolar em seus múltiplos desafios à classe trabalhadora na sua luta pela garantia do direito à educação.

\section{Considerações Finais}

O Estado Capitalista preocupa-se mais em desenvolver a pequena política do que a grande, já que, assim, não são superadas as condições de reprodução da ordem atual e mantémse a hegemonia das classes dominantes, por meio do consentimento da classe trabalhadora.

Muitos foram os que apostaram na tese de que a educação reproduzida e intencionada pelas classes dominantes seria capaz de 
fornecer uma completa análise crítica da realidade, acabando-se, assim, outras formas de educação. No entanto, não se atentaram para o fato de que o próprio capital em seu desenvolvimento sociometabólico desigual e contraditório não comporta somente uma forma de relação educacional: a formal. O ser humano ao se relacionar com outros, mediados pela vida produtiva, educam-se também. O imperialismo educacional hegemônico vigente cria, destrói e recria a educação popular e as lutas transformadoras, e é por esse processo dinâmico que podemos compreender a resistência de grupos e movimentos que resgatam o sentido da formação humana em tempos nossos de encruzilhadas. $\mathrm{Ou}$ nos mobilizamos, professores universitários e demais profissionais da área de educação, e implementamos estratégias e táticas rumo à melhoria educacional pública, ou assumimos, ao menos com a decência de estarmos conscientes, as consequências do nosso silêncio, que certamente fortalecerá interesses e ambições de grupos privados de dominação da educação como um elemento de garantia e perpetuação do status quo, como mecanismo ideológico que garante e reproduz o consentimento e, também, como elemento operante na lógica de subordinação e exploração da classe trabalhadora. A escola possui o potencial para se configurar como "porta de entrada" para uma articulação que permita a garantia dos direitos, porém este processo precisa ser construído teoricamente e na prática por educadores e educadoras verdadeiramente comprometidos com a formação humana.

\section{Referências}

BOTTOMORE, T. Dicionário do pensamento marxista. Rio de Janeiro: J. Zahar, 2001.

CALDART, R. S. Educação do campo. In: CALDART, R. S. et al. (Org.). Dicionário da educação do campo. São Paulo: Expressão Popular, 2012.

COUTINHO, C. N. A democracia como valor universal e outros ensaios. Rio de Janeiro: Salamandra, 1984.

FIAMENGUI, G. Impactos do Projeto São Paulo Faz Escola no trabalho do professor. 2009. 134 f. Dissertação (Mestrado em Educação) - Faculdade de Educação, Universidade de Santos, Santos, 2009.

FREIRE, P. Pedagogia da autonomia. São Paulo: Paz e Terra. 1996.

FREIRE, P. Pedagogia do oprimido. 11. ed. Rio de Janeiro: Paz e Terra, 1987.

FREIRE, P. Política e educação. 5. ed. São Paulo: Cortez, 2001.

GONZÁLES, J. L. C.; SALLES, F. C. Trabalho docente na era das incertezas. In: TUMOLO, P. S.; BATISTA, R. L. Trabalho economia e educação: perspectivas do capitalismo global. Londrina, PR: Práxis, 2008.

GRAMSCl, A. Maquiavel, a política e o estado moderno. Rio de Janeiro: Civilização Brasileira, 1976.

MARX, K. Manuscritos econômico-filosóficos. São Paulo: Boitempo, 2004. 
MARX, K. O 18 Brumário e Cartas a Kugelmann. Rio de Janeiro: Paz e Terra, 1997.

MÉSZÁROS, I. A educação para além do capital. São Paulo: Boitempo, 2008.

RANIERI, J. A câmara escura: alienação e estranhamento em Marx. São Paulo: Boitempo, 2001.

SANTOS, M. Por uma outra globalização: do pensamento único à consciência universal. 20. ed. Rio de Janeiro: Record, 2011.

Submetido em 18 de abril de 2013.

Aprovado em 19 de junho de 2013. 